\title{
IMICV fault analysis method with multiple PV grid-connected inverters for distribution systems
}

\author{
Ailson P. Moura a,b,*, J.A. Peças Lopes ${ }^{c}$, Adriano A.F. de Moura ${ }^{\mathrm{d}}$, \\ Jean Sumaili ${ }^{\mathrm{e}}$, C.L. Moreira ${ }^{\mathrm{C}}$ \\ a Department of Electrical Engineering, Federal University of Ceara, Pici Campus, Brazil \\ b CAPES Foundation, Brazil \\ ${ }^{\mathrm{c}}$ Faculty of Electrical and Computer Engineering, University of Porto, Instituto de Engenharia de Sistemas e Computadores do Porto(INESCPorto), \\ 4200-465 Porto, Portugal \\ d Department of Environmental Science and Technology, Federal Rural University of Semi-Arid, Av. Francisco Mota, 572 Bairro Costa e Silva, \\ Mossoró-RN CEP: 59.625-900, Brazil \\ e Instituto de Engenharia de Sistemas e Computadores do Porto(INESCPorto), 4200-465 Porto, Portugal
}

\section{A R T I C L E I N F O}

\section{Article history:}

Received 6 June 2014

Received in revised form 4 September 2014

Accepted 8 September 2014

Available online 29 September 2014

\section{Keywords:}

Distribution system

Fault analysis

Photovoltaic (PV)

Power system

Grid-connected photovoltaic system

Photovoltaic generators

\begin{abstract}
A B S T R A C T
A novel faults analysis method with multiple PV grid-connected inverters for distribution systems is proposed. The aforesaid proposed method Inverter Matrix Impedance Current Vector (IMICV) employs symmetrical components combined with a matrix denominated of Inverter Matrix Impedance and with a vector denominated Impedance-Current Vector which are formed by inspection. This matrix and this vector are used to solve a linear system of equations where the following post-fault variables are: current in substation, the voltage at the fault point and voltages in the PV grid-connected nodes. A comparison of results obtained using the new method with the results of the professional software ANAFAS validates the method proposed. Computer simulations show that the proposed method for classical shunt faults analysis is efficient, accurate and easy to program.
\end{abstract}

(C) 2014 Elsevier B.V. All rights reserved.

\section{Introduction}

The system of symmetrical components is used traditionally for the analysis of symmetrical and asymmetrical operation of distribution systems. Faults in general and short-circuit currents in particular are the most severe operating conditions in distribution systems. Each of the different faults, e.g., single-line-to-ground (LG), line-to-line (LL), line-to-line-to-ground (LLG) and three-phase (LLL) can be represented by an equivalent circuit diagram in the system of phase components and by this in the system of symmetrical components as well [1-3].

Over the last years energy shortage and environmental problems have been increasing seriously. Thus, humanity must adopt renewable energy and green energy in order to achieve a sustainable development.

\footnotetext{
* Corresponding author at: Department of Electrical Engineering, Federal University of Ceara, Pici Campus, Brazil. Tel.: +55 85 32413528; fax: +55 8533669574.

E-mail addresses: ailson@ufc.br (A.P. Moura),jpl@fe.up.pt (J.A.P. Lopes), adrianoaron@ieee.org (A.A.F. de Moura), jean.sumaili@inescporto.pt (J. Sumaili), cmoreira@inescporto.pt (C.L. Moreira).
}

Since creation of Czochralski process to make the first generation of single-crystal silicon photovoltaic, the photovoltaic (PV) systems have been utilized as renewable energy sources to produce electric power [4]. It is worth noting that PV power is becoming cheaper and cheaper every year, as a result it is expected to have a higher penetration level in power networks. Grid-connection of PV systems is accomplished through the inverter, which converts dc power generated from PV modules to ac power used for ordinary electric equipments power supply.

Since growth of PV systems accelerates, it has become important as the PV systems will contribute to the fault current during a fault. Several studies investigate the impact of a PV on the fault current levels on a feeder using mainly time domain simulation methods [5]. The following can be cited: Plet and Green proposed inverter fault models and their use in a network fault analysis [6]. Moreover, in [7], a novel unsymmetrical faults analysis method with hybrid compensation for microgrid distribution systems is proposed. This method employs the actual three-phase models to handle unsymmetrical faults. In [8], a fault analysis method for inverter-interfaced DGs was proposed. The method aims to estimate the initial high current that an inverter interfaced DG under voltage control scheme can inject during the first cycle of the 
fault. Ref. [9] proposed a methodology to establish a general index focused on the insertion of distributed photovoltaic generation and energy storage using batteries. Ting-Chia Ou proposed a direct building algorithm for microgrid distribution ground fault analysis [10]. In [11], MATLAB/SIMULINK is used to simulate single phase and three phase voltage source inverters which are increasingly being used to integrate electric power generation from solar photovoltaic with the electric distribution systems. Ref. [12], also used MATLAB/SIMULINK to present a model of grid-connected hybrid AC/DC microgrid. Furthermore, dynamic models for each system component are developed and used for short-time transient simulations. In [13], a PV inverter dynamic model in PSCAD/EMTDC is developed. In [14], the authors investigated the impacts of PV connection on the protection systems of a distribution network, especially when power flow is reversed in high penetration scenarios. Even though the substation model was built in a real-time EMTP type simulation environment using RTDS/RSCAD. However, the power system literature does not present a simple method, which can be used in real time. This method is based on solving a linear system inside an iterative process, meanwhile it calculates the fault current (on frequency domain) on radial distribution system connected with multiple PV generation.

In the Power Engineering and for the electric power industry real-time fault analysis is oriented toward applications in the distribution system operation area other than the planning analysis. The results of these earlier studies can be used for distribution adaptive relay coordination and settings when feeder reconfiguration is performed, which could be a useful future smart grid application [15].

This paper proposes a single and efficient method to calculate shunt fault current on a PV-dominated distribution feeder. The novel faults analysis method employs symmetrical components combined with a matrix denominated of inverter matrix impedance (IMI) and with a vector denominated impedancecurrent vector (ICV) which are formed by inspection. The proposed method is denominated Inverter Matrix Impedance Current Vector (IMICV).

The paper is organized as follows: Firstly, the photovoltaic system model is introduced. Secondly, a complete demonstration of the new method is presented, including a numerical example. In fourth section the new method is validated. Final conclusions and references are contained in this paper as well.

\section{Model of the photovoltaic system}

According to German standard VDE 4105 reducing the power factor (PF) of PV generation using fixed PF should be taken, whether inductive or capacitive, aimed at improving the operation of the PV system by the distribution network. Thus, a complete model for a PV system must represent active and reactive current components.

When a fault occurs on the feeder, the PV system feeds current to the fault. Due to the characteristics of the inverter, the fault current has only positive sequence component which depends on the PV inverter design. Since the PV systems are designed to push the maximum power available from PV panels to the system, the PV inverter tries to push this power even under low voltage conditions which occur during a fault, i.e., it will try to act like a constant power source [5]. Hence, the current injection from a PV inverter to the system can be approximated as in Eq. (1):

$I_{\text {post-fault(+) }}=\frac{P_{0}}{\left|V_{\text {post-fault(+) }}\right| P F}<\left(\operatorname{angle}\left(V_{\text {post-fault(+) }}\right)-\arccos (P F)\right)$

where $P_{0}$ is the power from the PV panels, $V_{\text {postfault(+) }}$ is the ac terminal positive sequence post-fault voltage and $\arccos (P F)$ is the arc cosine of the power factor.

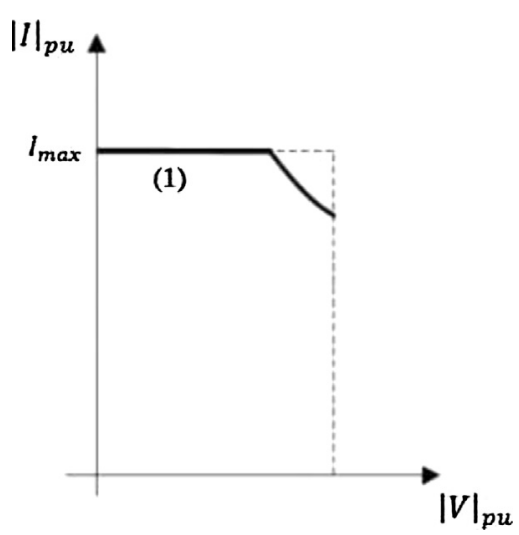

Fig. 1. V-I characteristics of a PV system.

However, if this current gets to be higher than the maximum current rating of the inverter, it will limit the current at its maximum level as shown in Eq. (2). Inverters limit their current to one to two times the rated current [5].

$I_{\text {post-fault(+) }}=\left|I_{\text {max-inverter }}\right|<\left(\operatorname{angle}\left(V_{\text {post-fault(+) }}\right)-\arccos (P F)\right)$

The V-I characteristics of a PV system is showed in Fig. 1.

According to Fig. 1, the PV system feeds current to the fault. If the three phase voltages are above of the nominal voltage, the magnitude of the injected current will be calculated so as to maintain the initial active power. I.e. the current is calculated by the Eq. (1). If the voltage gets too low, the magnitude of the current will reach its maximum limit $\left(I_{\max }\right)$ and it will not pass this value. The horizontal segment (1) in Fig. 1 presents this situation.

\section{New method formulation}

A complete demonstration of the IMICV method is presented hereafter, illustrated with a numerical example.

One of the most powerful matrices used in power system analysis is the bus impedance matrix (Z-Matrix). The Z-Matrix is generally full, i.e. it contains elements in every position unless there are disconnected parts of the network. Generally, an algorithm for finding the Z-Matrix is more direct and cheaper to implement than performing an inversion of admittance matrix [1].

The new method employs positive, negative and zero sequences components combined with the IMI and with ICV.

Initially, the proposed method requires the formation of the classical positive Z-Matrix and classical zero Z-Matrix [16] which are demanded to calculate the post-fault voltages.

The iterative process requires the setup of the post-fault voltages. Then, initial post-fault positive sequence voltages are calculated using the equations to follow:

LL fault

$v_{i_{+}}^{r}=1-\frac{z_{i, k}}{2\left(z_{k, k}\right)}$

LG fault

$v_{i_{+}}^{r}=1-\frac{z_{i, k}}{2\left(z_{k, k}\right)+z_{k, k}^{0}+3 z_{g}}$

LLG fault

$v_{i_{+}}^{r}=1-\frac{z_{i, k}}{z_{k, k}+\left(\left(\left(z_{k, k}\right)\left(z_{k, k}^{0}+3 z_{g}\right)\right) /\left(z_{k, k}+z_{k, k}^{0}+3 z_{g}\right)\right)}$

LLL fault

$v_{i_{+}}^{r}=1-\frac{z_{i, k}}{z_{k, k}}$ 


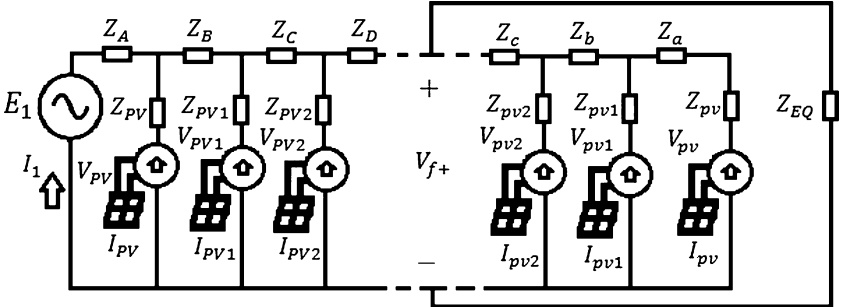

Fig. 2. Connections of positive, negative and zero impedances diagram.

where, $v_{i_{+}}^{r}$ - Post-fault positive sequence voltage at bus $r$; $Z_{k, k}$ - diagonal elements of the bus impedance matrix (positive sequence); $Z_{k . k}^{0}$ - diagonal elements of the of the bus impedance matrix (zero sequence); $Z_{i, k}$ - off-diagonal elements of the bus impedance matrix; $Z_{g}$ - fault impedance.

Before building the IMI, the power distribution system must be reduced by accumulating of positive sequence impedances in the main feeder and also in the secondary branches. Hence, this process is denominated reduced system and, is made as follows: Firstly, the accumulation process of positive sequence impedances occurs from the substation to the fault which consists in three other steps:

First step: Accumulation of positive sequence impedance between the substation and the first node where it locates a PV generation;

Second step: Accumulation of positive sequence impedance between the first node and the second node where it locates a PV generation. Similarly, this step is carried out until the last node before the fault, where it locates a PV generation;

Third step: Accumulation of positive sequence impedance between the last node where it locates a PV generation before the fault and the faulted node.

Afterwards, the accumulation of positive sequence impedances occurs as follows: from the faulted node until the last node after the faulted node. This process has two other steps:

Fourth step: Accumulation of positive sequence impedance between the faulted node and the first node where it locates a PV generation;

Fifth step: Accumulation of positive sequence impedance between the first node and the second node where it locates a PV generation. Similarly, this step is carried out until the last node after the fault.

Finally, it accumulates the positive sequence impedance between each node where there is a PV generation and the main feeder.

The IMI and ICV are obtained by using Kirchhoff's voltage law and getting the mesh equations. From these equations, simple rules are formulated to form this matrix and this vector by inspection.

The diagram in Fig. 2 illustrates how the positive, negative and zero sequence circuits are connected to the mesh equations in order to be written. In this diagram there are $N+M$ generation $\mathrm{PV}$, where $N$ is the number of the generation PV before the fault and $M$ is the number of the generation PV after the fault.

In Fig. 2 the positive sequence impedances, the positive sequence voltages and the positive sequence currents that have subscripts in uppercase letters, indicate the voltages, currents and impedances that appear from the substation to the fault point. Moreover, the positive sequence impedances, the positive sequence voltages and the positive sequence currents that have subscripts with lowercase letters, indicate the voltages, currents and impedances of the circuit that turn up on the other side of the fault point (right part of Fig. 2).

The equivalent impedance $\left(Z_{\mathrm{EQ}}\right)$ is the association of the negative sequence impedance $\left(Z_{-}\right)$and zero sequence impedance $Z_{0}$, which value depends on the type of fault. E.g.:
LL fault

The zero sequence network is open. Thus:

$Z_{E Q}=Z_{-}$

LG fault

This implies that the sequence networks must be connected in series. Therefore:

$Z_{E Q}=\left(Z_{-}\right)+\left(Z_{0}\right)$

LLG fault

The negative sequence network is in parallel with the zero sequence network. Then:

$Z_{E Q}=\frac{\left(Z_{-}\right)\left(Z_{0}\right)}{\left(Z_{-}\right)+\left(Z_{0}\right)}$

LLL fault

The currents are balanced and only the positive sequence network is operating. Therefore:

$Z_{E Q}=0$

The rules for forming the IMI and ICV are applied to the reduced system and they are the following:

A. IMI

A1. The diagonal elements (index ii):

(A11) Element with index 11 - Sum of the impedances of the main feeder from the substation to the fault, with opposite sign.

(A12) Element with index 22 - always null.

(A13) Other elements with indices ii: If the branch connected to node $j=i-1$ has a PV generation, then the element will have an unit value. However, if the branch connected to node $j=i-1$ has no PV generation, then the element will be null.

A2. Off-diagonal elements (index ij):

(A21) Element with index 12 is equal -1 .

(A22) Element with index 21: Sum of the impedances of the main feeder from the substation to the fault added to the equivalent impedance, with opposite sign.

(A23) Other elements with indices i1: (f1) PV generation sources before the fault: Sum of the impedances of the main feeder, after its respective generation PV, from the substation to the fault added to the equivalent impedance, with opposite sign; (f2) PV generation sources after the fault: Equivalent impedance with opposite sign.

(A24) Other elements with indices ij: null.

B. ICV

B1. Element 11: $-1+\Sigma_{\mathrm{PV} \text { before }}$ (impedances of the main feeder from the generation source $i$ to the fault) $\times$ generation source current $i]$.

B2. Element 21: $-1+\Sigma_{\mathrm{PV} \text { before }}$ (impedances of the main feeder from the generation source $i$ to the fault + equivalent impedance) $\times$ generation source current $i]+\Sigma_{\mathrm{PV} \text { after }}$ (equivalent impedance) $\times$ generation source current $k$ ]

B3. Elements $3 \ldots(3+N-1), 1$ (they are related with power generation $\mathrm{PV}$ before the fault), where $N$ is the number of the generation PV before the fault: (Sum of the impedances from generation source $i$ to the fault + equivalent impedance) $\times$ generation source current $i+\Sigma_{\text {PV before }}$ (impedances of the main feeder from the generation source $j$ to the fault + equivalent impedance) $\times$ generation source current $j]+\Sigma_{\mathrm{PV} \text { after }}$ (equivalent impedance) $\times$ generation source current $k]$.

B4. Elements $N+2 \ldots(M+N), 1$ (they are related with power generation PV after the fault), where $M$ is the number of the generation PV after the fault. The calculation of the elements is done in a similar way as in the (B3) item. 


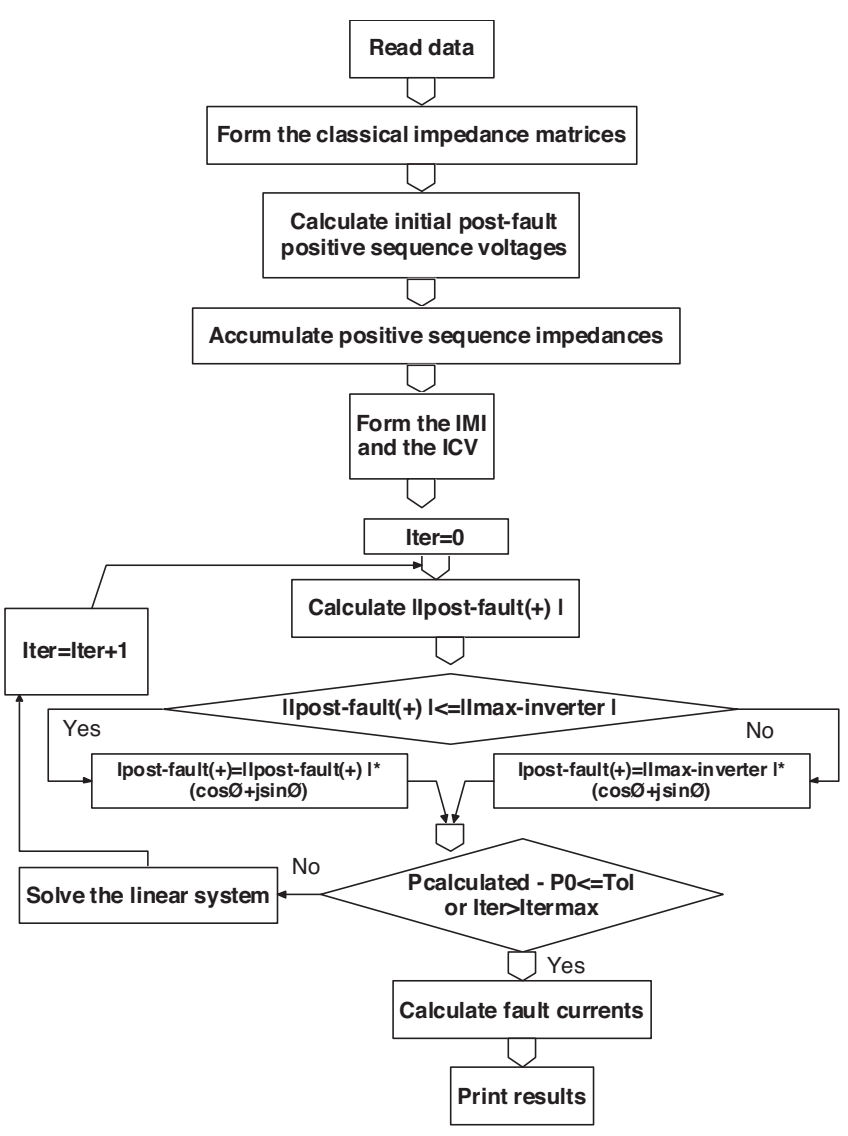

Fig. 3. Basic flowchart of the proposed method.

where: $\Sigma_{\mathrm{PV} \text { before }}$ is a sum related with power generation PV before of the fault; $\Sigma_{\mathrm{PV} \text { after }}$ is a sum related with power generation PV after of the fault.

Take for example, a distribution system which considers three generations PV of the substation side and three generations PV after the fault point. In this example, the line diagram is the same as in Fig. 2 by removing the dashed lines. The mesh equations allow to write the following linear system of equations:

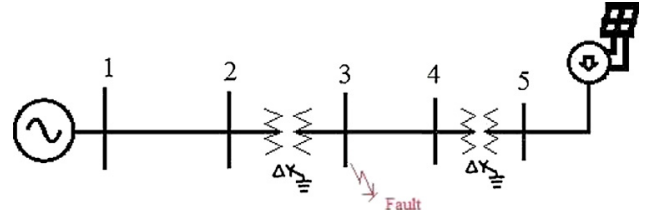

Fig. 4. Small distribution system.

According to Fig. 2, the calculated fault current is given by Eq. (8).

$$
I_{F}=I_{1}+I_{P V}+I_{P V 1}+I_{P V 2}+\cdots+I_{p v 2}+I_{p v 1}+I_{p v}
$$

C. Simulation of a small system

In this particular item, we will give a numerical example to illustrate the IMICV fault analysis method.

Consider the distribution system shown in Fig. 4. The three-phase short-circuit power and single-phase short-circuit power of the bus 1 are respectively: $4808 \angle-80^{\circ}$ MVA and $4109 \angle-80^{\circ} \mathrm{MVA}$. The two transformers are delta-grounded wye and their data are: T23-138/11.95 kV-15 MVA-8.68\%. T45 - 11.95/0.22 kV-500 kVA - 5\%. The data distribution lines are: L12: $Z_{\text {positive }}=0.1902+\mathrm{j} 0.4808 \mathrm{ohms} / \mathrm{km}$, $Z_{\text {zero }}=0.4414+\mathrm{j} 1.7452 \mathrm{ohms} / \mathrm{km}$, distribution line length $=$ $10 \mathrm{~km}, \quad$ L34: $\quad Z_{\text {positive }}=0.1903+\mathrm{j} 0, \quad 3922 \mathrm{ohms} / \mathrm{km}$, $Z_{\text {zero }}=0.4359+\mathrm{j} 1.8540 \mathrm{ohms} / \mathrm{km}$, distribution line length $=0.8 \mathrm{~km}$. Fault phase-earth occurs on bus 3 (Phase A), calculate: (1) The fault current, (2) The current contribution of the PV generator.

The injected power of the PV generator is $500 \mathrm{~kW}$. The distribution system base is 100 MVA.

The calculations follow the basic flowchart. The nomenclature is the same as in Fig. 2.

1. Calculation of impedance matrix elements (pu)

$$
\begin{aligned}
& Z 33_{\text {positive }}=0.0136+0.6244 i \\
& Z 53_{\text {positive }}=0.0136+0.6244 i
\end{aligned}
$$

$$
\left[\begin{array}{llllllll}
-\left(Z_{A}+Z_{B}+Z_{C}+Z_{D}\right) & -1 & 0 & 0 & 0 & 0 & 0 & 0 \\
-\left(Z_{A}+Z_{B}+Z_{C}+Z_{D}+Z_{E Q}\right) & 0 & 0 & 0 & 0 & 0 & 0 & 0 \\
-\left(Z_{B}+Z_{C}+Z_{D}+Z_{E Q}\right) & 0 & 1 & 0 & 0 & 0 & 0 & 0 \\
-\left(Z_{C}+Z_{D}+Z_{E Q}\right) & 0 & 0 & 1 & 0 & 0 & 0 & 0 \\
-\left(Z_{D}+Z_{E Q}\right) & 0 & 0 & 0 & 1 & 0 & 0 & 0 \\
-Z_{E Q} & 0 & 0 & 0 & 0 & 1 & 0 & 0 \\
-Z_{E Q} & 0 & 0 & 0 & 0 & 0 & 1 & 0 \\
-Z_{E Q} & 0 & 0 & 0 & 0 & 0 & 0 & 1
\end{array}\right]\left[\begin{array}{l}
I_{1} \\
V_{f+} \\
V_{P V} \\
V_{P V 1} \\
V_{P V 2} \\
V_{p v} \\
V_{p v 1} \\
V_{p v 2}
\end{array}\right]=\left[\begin{array}{l}
-1+\left(Z_{B}+Z_{C}+Z_{D}\right) I_{P V}+\left(Z_{C}+Z_{D}\right) I_{P V 1}+\left(Z_{D}\right) I_{P V 2} \\
-1+\left(Z_{B}+Z_{C}+Z_{D}+Z_{E Q}\right) I_{P V}+\left(Z_{C}+Z_{D}+Z_{E Q}\right) I_{P V 1}+\left(Z_{D}+Z_{E Q}\right) I_{P V 2}+Z_{E Q}\left(I_{p v}+I_{p v 1}+I_{p v 2}\right) \\
\left(Z_{P V}+Z_{B}+Z_{C}+Z_{D}+Z_{E Q}\right) I_{P V}+\left(Z_{C}+Z_{D}+Z_{E Q}\right) I_{P V 1}+\left(Z_{D}+Z_{E Q}\right) I_{P V 2}+Z_{E Q}\left(I_{p v}+I_{p v 1}+I_{p v 2}\right) \\
\left(Z_{C}+Z_{D}+Z_{E Q}\right) I_{P V}+\left(Z_{P V 1}+Z_{C}+Z_{D}+Z_{E Q}\right) I_{P V 1}+\left(Z_{D}+Z_{E Q}\right) I_{P V 2}+Z_{E Q}\left(I_{p v}+I_{p v 1}+I_{p v 2}\right) \\
\left(Z_{D}+Z_{E Q}\right) I_{P V}+\left(Z_{D}+Z_{E Q}\right) I_{P V 1}+\left(Z_{P V 2}+Z_{D}+Z_{E Q}\right) I_{P V 2}+Z_{E Q}\left(I_{p v}+I_{p v 1}+I_{p v 2}\right) \\
\left(Z_{a}+Z_{p v}+Z_{b}+Z_{E Q}\right) I_{p v}+\left(Z_{b}+Z_{c}+Z_{E Q}\right) I_{p v 1}+\left(Z_{c}+Z_{E Q}\right) I_{p v 2}+Z_{E Q}\left(I_{P V}+I_{P V 1}+I_{P V 2}\right) \\
\left(Z_{b}+Z_{c}+Z_{E Q}\right) I_{p v}+\left(Z_{b}+Z_{c}+Z_{E Q}+Z_{p v 1}\right) I_{p v 1}+\left(Z_{c}+Z_{E Q}\right) I_{p v 2}+Z_{E Q}\left(I_{P V}+I_{P V 1}+I_{P V 2}\right) \\
\left(Z_{c}+Z_{E Q}\right) I_{p v}+\left(Z_{c}+Z_{E Q}\right) I_{p v 1}+\left(Z_{c}+Z_{E Q}+Z_{p v 2}\right) I_{p v 2}+Z_{E Q}\left(I_{P V}+I_{P V 1}+I_{P V 2}\right)
\end{array}\right]
$$

The IMI and the ICV are used to solve a linear system of equations where the following post-fault variables are: current in substation, the voltage at the fault point and voltages in the PV grid-connected nodes.

Fig. 3 presents the basic flowchart of the proposed method.

The calculated active power is given by Eq. (11).

$P_{\text {calculated }}=3 \cdot V_{\text {post-fault(+) }} \cdot I_{\text {post-fault(+) }}^{*} \cdot S_{\text {base }}$

In basic flowchart P0 is the specified active power for PV generation (MW).

$$
\begin{aligned}
& Z 33_{\text {zero }}=0.0+0.5787 i \\
& Z 53_{\text {zero }}=0.0+0.0 i
\end{aligned}
$$

2. Calculation of the initial post-fault positive sequence voltage (pu). According to Eq. (4):

$$
v_{3+}=1-\frac{Z_{5,3}}{2\left(Z_{3,3}\right)+Z_{3,3}^{0}+3(0)}=0.9804 \angle-0.1988^{\circ}
$$


3. Accumulation of positive sequence impedances

$$
\begin{aligned}
& Z_{A}=0.0136+0.6244 i \\
& Z_{a}=0.1066+10.2197 i
\end{aligned}
$$

4. IMI and ICV calculation

$$
\begin{aligned}
I M I & =\left[\begin{array}{lll}
-0.1202-10.8441 i & -1 & 0 \\
-0.2404-31.6882 i & 0 & 0 \\
-0.2268-31.0638 i & 0 & 1
\end{array}\right] \\
I C V & =\left[\begin{array}{l}
-0.9995+0.0776 i \\
-0.9991+0.2359 i \\
0.0009+0.2359 i
\end{array}\right]
\end{aligned}
$$

5. Iterative process

Tolerance $=0.00001 \mathrm{pu}$

Convergence iteration numbers $=3$

$$
\begin{aligned}
& I_{F}=0.0316 \angle-89.3829^{\circ} \mathrm{pu} \\
& I_{p v}=0.0051 \angle-0.1988^{\circ} \mathrm{pu}
\end{aligned}
$$

\section{Validating the proposed method}

Fault currents calculation is a key factor in determining the tap settings of the protection relays for many practical applications.

The commercial software Simultaneous Fault Analysis (ANAFAS), developed by the Electric Energy Researches Center (CEPEL) - Brazil, was used just for verification of the fault currents calculation.

This study was performed on the regional distribution system that consists of a three-phase radial distribution feeder with urban and rural branches. The test feeder used was called LOC-36 and its data are stated in Appendix. This feeder is located in the distribution system of the Energy Company of Ceara - Brazil. LOC-36 has 36 buses, 35 branches and its three-phase short-circuit power is $505.59 \angle 59.10^{\circ} \mathrm{MVA}$. The transformer substation is delta-grounded wye and their data are: $69 / 13.8 \mathrm{kV}-6 \%$ in the system base. The single-line diagram of the feeder LOC-36 is showed in Fig. 5.

The simulated solar plants were based on photovoltaic panels SX 120U model (manufacturer solar PB).

The integration of PV generation units are given as follows: 330 units of generator PV were installed in bus $4 ; 110$ units of generator PV were installed in bus 13 and 990 units of generator PV were installed in bus 19 , totaling respectively, $0.957 \mathrm{MW}(\mathrm{PF}=1)$, $0.319 \mathrm{MW}(\mathrm{PF}=1)$ and $2.817 \mathrm{MW}(\mathrm{PF}=0.92$ inductive) of rated power. The computer used in these simulations, is a DELL computer with Intel(R)Core(TM) i7-3632QM CPU @ 2.20 GHz, Memory(RAM)

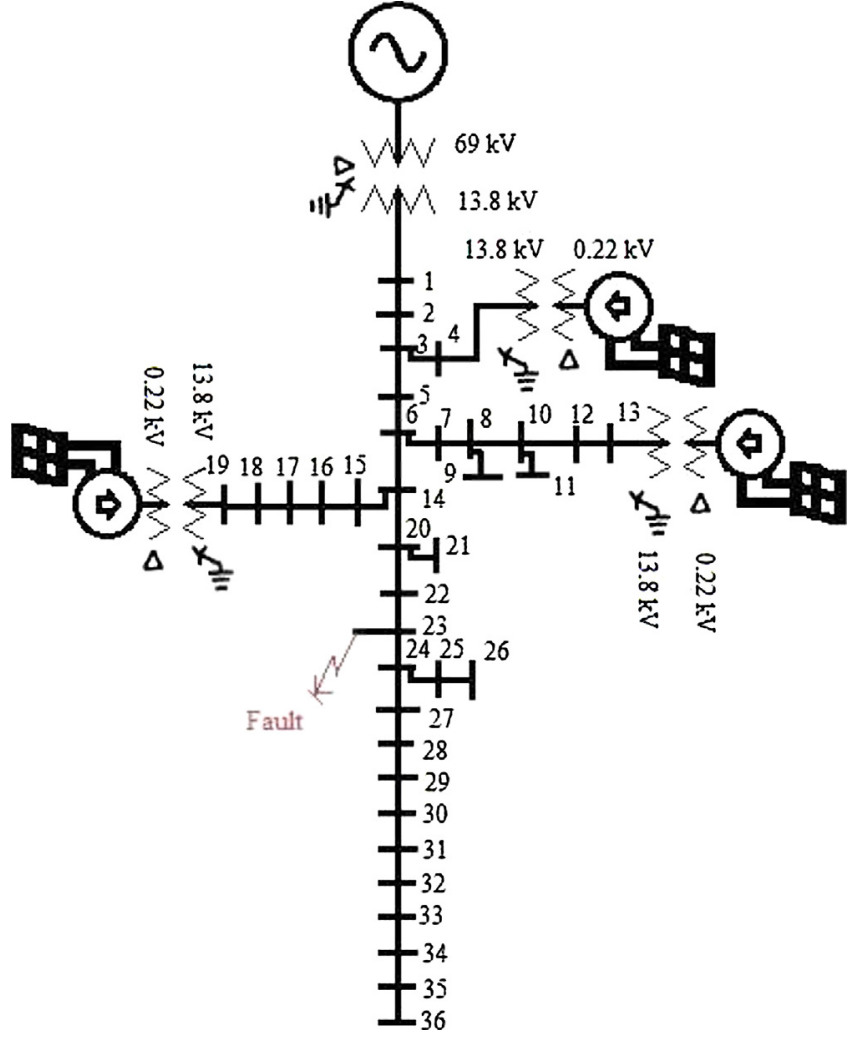

\begin{tabular}{|c|c|c|c|c|c|c|}
\hline \multirow[t]{2}{*}{ Fault type } & \multicolumn{3}{|c|}{ Phase current absolute value ANAFAS (pu) } & \multicolumn{3}{|c|}{ Phase current absolute value IMICV (pu) } \\
\hline & $I_{A}$ & $I_{B}$ & $I_{C}$ & $I_{A}$ & $I_{B}$ & $I_{C}$ \\
\hline LG A & 0.590 & 0 & 0 & 0.5915 & 0 & 0 \\
\hline LG B & 0 & 0.590 & 0 & 0 & 0.5915 & 0 \\
\hline LG C & 0 & 0 & 0.590 & 0 & 0 & 0.5915 \\
\hline LL AB & 0.811 & 0.811 & 0 & 0.8166 & 0.8166 & 0 \\
\hline LL BC & 0 & 0.811 & 0.811 & 0 & 0.8166 & 0.8166 \\
\hline LL AC & 0.811 & 0 & 0.811 & 0.8166 & 0 & 0.8166 \\
\hline LLG AB & 0.772 & 0.901 & 0 & 0.7764 & 0.9076 & 0 \\
\hline LLG BC & 0 & 0.772 & 0.901 & 0 & 0.7764 & 0.9076 \\
\hline LLG AC & 0.901 & 0 & 0.772 & 0.9076 & 0 & 0.7764 \\
\hline LLL & 0.945 & 0.945 & 0.945 & 0.9513 & 0.9513 & 0.9513 \\
\hline
\end{tabular}

Fig. 5. Feeder LOC-36 diagram.

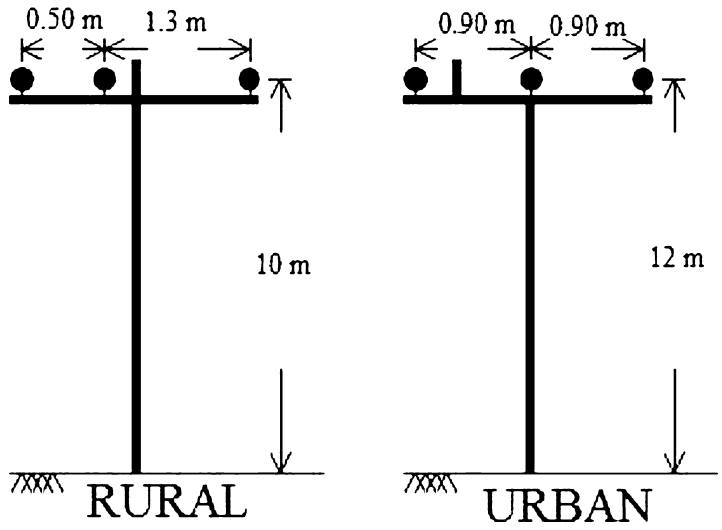

Fig. 6. Overhead line spacings.

Table 1

Fault current results - bus 23. 
Table 2

Fault currents percent errors.

\begin{tabular}{ll}
\hline Fault type & Abs (error) (\%) \\
\hline LG & 0.25 \\
LL & 0.69 \\
LLG & 0.57 and 0.73 \\
LLL & 0.67 \\
\hline
\end{tabular}

Table 3

Fault currents of the PV generations.

\begin{tabular}{lll}
\hline Fault type - bus & $\begin{array}{l}\text { PV current absolute } \\
\text { value (pu) ANAFAS }\end{array}$ & $\begin{array}{l}\text { PV current absolute } \\
\text { value (pu) IMICV }\end{array}$ \\
\hline LG -4 & 0.010 & 0.0100 \\
LG -13 & 0.003 & 0.0034 \\
LG -19 & 0.034 & 0.0337 \\
LL -4 & 0.011 & 0.0109 \\
LL -13 & 0.004 & 0.0040 \\
LL -19 & 0.039 & 0.0393 \\
LLG - 4 & 0.011 & 0.0111 \\
LLG -13 & 0.004 & 0.0042 \\
LLG -19 & 0.041 & 0.0411 \\
LLL -4 & 0.013 & 0.0128 \\
LLL -13 & 0.005 & 0.0055 \\
LLL -19 & 0.055 & 0.0547 \\
\hline
\end{tabular}

Table 4

Number of iterations for IMICV convergence and CPU time.

\begin{tabular}{lll}
\hline Fault type & Iterations number & Total execution time $(\mathrm{s})$ \\
\hline LG & 4 & 0.0049 \\
LL & 4 & 0.0048 \\
LLG & 5 & 0.0060 \\
LLL & 4 & 0.0049 \\
\hline
\end{tabular}

$8 \mathrm{~GB}$ and 64-bits OS. The IMICV fault analysis method was written in MATLAB code. Afterwards, the results obtained from ANAFAS and IMICV were compared.

Table 1 shows a comparison of the fault currents on bus 23 of the feeder LOC-36 in both programs described above. Table 2 shows the percent errors obtained, respectively, with ANAFAS and with the IMICV.

According to Tables 1 and 2 the results from IMICV and the results from ANAFAS can be seen to be much closer. The largest error is $0.73 \%$.

Table 3 illustrates the results of the fault currents of the PV generations located on buses 4, 13 and 19. The results of ANAFAS software report only three decimal digits. One understands then that the results from IMICV and the results from ANAFAS also can be seen to be much closer. Therefore, the IMICV proposed method can be considered as validated.

Table 4 presents the convergence iteration numbers for IMICV and total execution time. Here, the value of the specified tolerance was $0.00001 \mathrm{pu}$. Furthermore, the largest iteration number occurred for LLG. Nevertheless, the number of iterations for convergence made by ANAFAS is not accessible in its results file. Finally, the total execution time of the IMICV shows that this tool is appropriate for the electric power industry real-time fault analysis.

\section{Conclusion}

A novel IMICV fault analysis method is developed in this paper. The proposed method can be used to simulate radial distribution system with multiple PV grid-connected inverters and, also for real-time fault analysis. The numerical results were compared with results of the professional software ANAFAS and the proposed method was validated. Computer simulations show that the proposed method is efficient, accurate and easy to program. Therefore, the new method can be a useful tool for the electric power industry.

\section{Appendix.}

Data from the feeder LOC-36 are shown below.

CONDUCTOR DATA and LENGTH OF THE DISTRIBUTION LINES.

\begin{tabular}{|c|c|c|c|c|c|}
\hline Size/stranding/material & From & To & $\begin{array}{l}\text { Line length } \\
\text { feet }\end{array}$ & $R(\Omega /$ mile $)$ & $\begin{array}{l}\text { GMR } \\
\text { feet }\end{array}$ \\
\hline 266,800/26/7//ACSR & 1 & 2 & 197 & 0.385 & 0.0217 \\
\hline 266,800/26/7//ACSR & 2 & 3 & 656 & 0.385 & 0.0217 \\
\hline $4 /$ & 3 & 4 & 3083 & 2.57 & 0.00437 \\
\hline \multicolumn{6}{|l|}{$6 / 1$} \\
\hline $266,800 / 26 / 7 / /$ ACSR & 3 & 5 & 2230 & 0.385 & 0.0217 \\
\hline $266,800 / 26 / 7 / /$ ACSR & 5 & 6 & 525 & 0.385 & 0.0217 \\
\hline $1 / 0$ & 6 & 7 & 3149 & 1.12 & 0.00446 \\
\hline \multicolumn{6}{|l|}{ ACSR } \\
\hline 4/ & 7 & 8 & 5871 & 2.57 & 0.00437 \\
\hline \multirow{2}{*}{\multicolumn{6}{|c|}{$\begin{array}{l}6 / 1 \\
\text { /ACSR }\end{array}$}} \\
\hline & & & & & \\
\hline $4 /$ & 8 & 9 & 1476 & 2.57 & 0.00437 \\
\hline \multicolumn{6}{|l|}{$6 / 1$} \\
\hline \multicolumn{6}{|l|}{ |ACSR } \\
\hline $4 /$ & 8 & 10 & 2624 & 2.57 & 0.00437 \\
\hline \multirow{2}{*}{\multicolumn{6}{|c|}{$6 / 1$}} \\
\hline |ACSR & & & & & \\
\hline $4 /$ & 10 & 11 & 1148 & 2.57 & 0.00437 \\
\hline \multirow{2}{*}{\multicolumn{6}{|c|}{$\begin{array}{l}6 / 1 \\
\text { /ACSR }\end{array}$}} \\
\hline & & & & & \\
\hline $4 /$ & 10 & 12 & 2788 & 2.57 & 0.00437 \\
\hline \multicolumn{6}{|l|}{$6 / 1$} \\
\hline \multicolumn{6}{|l|}{ /ACSR } \\
\hline $4 /$ & 12 & 13 & 2427 & 2.57 & 0.00437 \\
\hline \multirow{2}{*}{\multicolumn{6}{|c|}{$6 / 1$}} \\
\hline & & & & & \\
\hline 266,800/26/7//ACSR & 6 & 14 & 164 & 0.385 & 0.0217 \\
\hline $1 / 0$ & 14 & 15 & 426 & 1.12 & 0.00446 \\
\hline \multicolumn{6}{|l|}{ ACSR } \\
\hline $1 / 0$ & 15 & 16 & 1148 & 1.12 & 0.00446 \\
\hline ACSR & & & & & \\
\hline $1 / 0$ & 16 & 17 & 492 & 1.12 & 0.00446 \\
\hline ACSR & & & & & \\
\hline $1 / 0$ & 17 & 18 & 262 & 1.12 & 0.00446 \\
\hline ACSR & & & & & \\
\hline $1 / 0$ & 18 & 19 & 230 & 1.12 & 0.00446 \\
\hline ACSR & & & & & \\
\hline 266,800/26/7//ACSR & 14 & 20 & 1640 & 0.385 & 0.0217 \\
\hline $95 /$ & 20 & 21 & 7675 & 0.356 & 0.01506 \\
\hline COPPER & & & & & \\
\hline $1 / 0$ & 20 & 22 & 2493 & 1.12 & 0.00446 \\
\hline ACSR & & & & & \\
\hline $1 / 0$ & 22 & 23 & 886 & 1.12 & 0.00446 \\
\hline ACSR & & & & & \\
\hline $1 / 0$ & 23 & 24 & 394 & 1.12 & 0.00446 \\
\hline ACSR & & & & & \\
\hline $4 /$ & 24 & 25 & 2624 & 2.57 & 0.00437 \\
\hline $6 / 1$ & & & & & \\
\hline /ACSR & & & & & \\
\hline $4 /$ & 25 & 26 & 754 & 2.57 & 0.00437 \\
\hline $6 / 1$ & & & & & \\
\hline /ACSR & & & & & \\
\hline $25 /$ & 24 & 27 & 3542 & 1,429 & 0.00794 \\
\hline $\mathrm{AA}$ & & & & & \\
\hline $25 /$ & 27 & 28 & 5904 & 1,429 & 0.00794 \\
\hline $\mathrm{AA}$ & & & & & \\
\hline $25 /$ & 28 & 29 & 394 & 1,429 & 0.00794 \\
\hline AA & & & & & \\
\hline $25 /$ & 29 & 30 & 853 & 1,429 & 0.00794 \\
\hline AA & & & & & \\
\hline $25 /$ & 30 & 31 & 3608 & 1,429 & 0.00794 \\
\hline AA & & & & & \\
\hline $25 /$ & 31 & 32 & 3018 & 1,429 & 0.00794 \\
\hline
\end{tabular}




\section{Appendix (Continued)}

\begin{tabular}{llllll}
\hline Size/stranding/material & From & To & $\begin{array}{l}\text { Line length } \\
\text { feet }\end{array}$ & $R(\Omega /$ mile $)$ & $\begin{array}{l}\text { GMR } \\
\text { feet }\end{array}$ \\
\hline $\begin{array}{l}25 / \\
\text { AA } \\
25 /\end{array}$ & 32 & 33 & 3772 & 1,429 & 0.00794 \\
AA & 33 & 34 & 787 & 1,429 & 0.00794 \\
$25 /$ & 34 & 35 & 2952 & 1,429 & 0.00794 \\
AA & 35 & 36 & 2296 & 1,429 & 0.00794 \\
$25 /$ & & & & & \\
AA & & & & &
\end{tabular}

Fig. 6 shows the spacing distances among phase conductors used for overhead distribution lines.

\section{References}

[1] P.M. Anderson, Analysis of Faulted Power Systems. Power Systems Engineering Series, IEEE Press, New York, USA, 1995.

[2] J. Duncan Glover, M.S. Sarma, T.J. Overbye, Power System Analysis \& Designs, 5th ed., Thomson Learning, Stamford, USA, 2011.

[3] J.J. Grainger, W.D. Stevenson Jr., Power System Analysis, McGraw-Hill, Inc., New York, USA, 1994

[4] G.M. Masters, Renewable and Efficient Electric Power Systems, John Wiley \& Sons, New York, USA, 2004

[5] H. Hooshyar, M.E. Baran, Fault analysis on distribution feeders with high penetration of PV systems, IEEE Trans. Power Syst. 28 (August) (2013) 2890-2896.
[6] C.A. Plet, T.C. Green, Fault response of inverter interfaced distributed generators in grid-connected applications, Electr. Power Syst. Res. 106 (2014) 21-28.

[7] T.-C. Ou, A novel unsymmetrical faults analysis for microgrid distribution systems, Int. J. Electr. Power Energy Syst. 43 (2012) 1017-1024.

[8] M.E. Baran, I. El-Markaby, Fault analysis on distribution feeders with distributed generators, IEEE Trans. Power Syst. 20 (November) (2005) $1757-1764$.

[9] O.M. Toledo, D. Oliveira Filho, A.S.A.C. Diniz, J.H. Martins, M.H.M. Vale, Methodology for evaluation of grid-tie connection of distributed energy resources case study with photovoltaic and energy storage, IEEE Trans. Power Syst. 28 (2013) 1132-1139.

[10] T.-C. Ou, Ground fault current analysis with a direct building algorithm for microgrid distribution, Int. J. Electr. Power Energy Syst. 53 (2013) 867-875.

[11] S.P. Pokharel, S.M. Brahma, S.J. Ranade, Modeling and simulation of three phase inverter for fault study of microgrids, in: North American Power Symposium (NAPS), 2012.

[12] F. Ding, K.A. Loparo, C. Wang, Modeling and simulation of grid-connected hybrid AC/DC microgrid, Power Energy Soc. Gen. Meet. (2012) 1-8.

[13] E. Muljadi, M. Singh, R. Bravo, V. Gevorgian, Dynamic model validation of PV inverters under short-circuit Conditions, Green Technol. Conf. (2013) 98-104.

[14] H. Ravindra, M.O. Faruque, P. McLaren, K. Schoder, M. Steurer, R. Meeker, Impact of PV on distribution protection system, in: North American Power Symposium (NAPS), 2012

[15] M.E. Baran, H. Hooshyar, Z. Shen, A. Huang, Accommodating high PV penetration on distribution feeders, IEEE Trans. Smart Grid 3 (June) (2012) 1039-1046.

[16] A.P. Moura, A.A.F. Moura, André A.F. Moura, Analysis of injected apparent power and flicker in a distribution network after wind power plant connection, IET Renew. Power Gener. 2 (2008) 113-122. 